\title{
Los enemigos y los efectos racionales del odio. Variaciones sobre temas de Plutarco
}

\author{
GustAVO ORTIZ-MiLLÁN \\ Instituto de Investigaciones Filosóficas \\ Universidad Nacional Autónoma de México \\ gustavo@filosoficas.unam.mx
}

\begin{abstract}
Resumen: En este artículo defiendo la idea de que, más que interferir con la racionalidad, algunas emociones pueden ser útiles para desarrollar formas racionales de pensamiento y acción. Esto lo sustento a partir del caso del odio, y específicamente del odio a los enemigos. Argumento que esta clase de odio puede ayudarnos a desplegar tanto formas epistémicas como prácticas de racionalidad. El odio puede generar modos racionales de formación de creencias al proveer un marco para los parámetros que se tomarán en cuenta en procesos de percepción y atención. También limita el número de consideraciones prácticas que pueden permitirnos alcanzar nuestros fines - determinadas por las tendencias a la acción características del odio-, al tiempo que desarrolla una forma estratégica de racionalidad. Finalmente, sostengo que el odio puede incluso tener consecuencias positivas para la conducta moral. Estos temas fueron presentados originalmente por Plutarco en su Moralia; aquí desarrollo algunas variaciones.
\end{abstract}

Palabras clave: odio, enemigos, emociones, racionalidad práctica, racionalidad epistémica

Abstract: In this paper I defend the idea that rather than disrupting rationality, certain emotions may actually help us to develop rational ways of thinking and acting. I make the case for the emotion of hatred, and more specifically to the case of hatred towards enemies. I argue that this kind of hatred may make us develop epistemic and practical forms of rationality. Hatred may generate rational ways of belief-formation by framing the parameters taken into account in perception and attention, and by bringing into light only a small portion of the epistemic information available. This emotion also narrows down the number of practical considerations that may help us to achieve our goals, while developing a strategic form of rationality-determined by the characteristic action tendencies of hatred. Finally, I argue that hatred may even have positive consequences in our moral conduct. These were topics originally developed by Plutarch in his Moralia, here I develop some variations.

Key words: hatred, enemies, emotions, practical rationality, epistemic rationality

The worst sin towards our fellow creatures is not to hate them, but to be indifferent to them; that's the essence of inhumanity.

GeOrge Bernard Shaw, The Devil's Disciple, acto II

\section{Contra el dualismo emociones/racionalidad. Los enemigos que odiamos}

Un viejo lugar común nos dice que las emociones son perturbadoras potenciales de la racionalidad. Tradicionalmente se ha pensado que las emociones son impulsos o pulsiones que interfieren en nuestra capacidad de formar juicios y creencias de forma racional, y de hacer elecciones y actuar 
racionalmente. Racionalidad y emociones, razón y pasiones, son parte de una dualidad cuyos dos elementos parecen tener ámbitos muy distintos y separados, y pertenecer a provincias separadas de la mente, como decía Hume. La noción de racionalidad parece excluir cualquier intromisión de las emociones; éstas son un modelo de motivos irreflexivos y completamente subjetivos, y cuando aparecen en la justificación de nuestros juicios y acciones se tiene razón suficiente para sospechar que esta justificación puede no ser objetiva o no estar guiada por la lógica y por una adecuada reflexión. Sin duda es cierto que en muchos casos las emociones perturban el razonamiento claro y racional, pero no es menos que ellas pueden ser en él piezas clave sin las cuales el pensamiento y la conducta racionales en general no podrían tenerse en pie. Estudios recientes en neurociencias, por ejemplo, han mostrado que las emociones y los sentimientos son un sistema de soporte sin el cual el edificio de la racionalidad no podría funcionar de manera apropiada y podría incluso llegar a derrumbarse: decisiones racionales requieren el apoyo de emociones y sentimientos, y no sólo de la lógica. ${ }^{1}$ Las emociones son parte de nuestro pensamiento reflexivo porque son razones para actuar y para juzgar tanto como lo son las creencias, los deseos y las intenciones. De hecho, están entre las razones más comunes que tenemos para actuar: sin ellas, probablemente habría pocas razones para actuar.

En este ensayo quiero defender la idea de que, más que perturbar la racionalidad, ciertas emociones pueden de hecho ayudarnos a desarrollar formas racionales de pensamiento y acción. No estoy diciendo que las emociones puedan siempre producir efectos racionales en la conducta, porque esto sería obviamente falso. Los efectos que en la racionalidad pueden tener algunas emociones son contingentes a circunstancias particulares. Hasta cierto punto es verdadera la teoría tradicional que considera que las emociones perturban la racionalidad; pero si este mecanismo es más común de lo que parece, el mecanismo opuesto, el de ayuda al pensamiento racional, es también común. Ambos mecanismos son posibles. Entiendo "mecanismos" como los define Jon Elster, como "patrones causales que ocurren frecuentemente y que son fácilmente reconocibles, y que son provocados en condiciones generalmente desconocidas o con consecuencias indeterminadas. Ellos nos permiten explicar, pero no predecir." ${ }^{2}$ Hay patrones causales reconocibles que provocan que las emociones tengan distintos efectos, pero éstos son indeterminados y muchas veces imposibles de predecir. Es difícil depender de una explicación nomológica para explicar cuándo las emociones desempeñan un papel y cuándo otro, o incluso hacer generalizaciones sobre las condiciones que conducirían a uno u otro efecto.

\footnotetext{
${ }^{1}$ Cfr. Antonio Damasio, Descartes' Error. Emotion, Reason, and the Human Brain; Joseph LeDoux, The Emotional Brain: The Mysterious Underpinnings of Emotional Life.

${ }^{2}$ Jon Elster, Alchemies of the Mind. Rationality and the Emotions, p. 1.
} 
Aquí argumentaré, más que sobre la racionalidad de las emociones en sí, cómo éstas pueden generar patrones racionales de formación de creencias y acciones. No pretendo generalizar mi tesis para toda clase de emociones, especialmente porque sospecho que no se aplica a todas - piénsese en las caracterizadas por reacciones viscerales, como la furia, el pánico o la angustia-. Dado que las emociones son muy diversas, voy a limitar mi tesis al caso del odio. Tal vez algunas de las conclusiones a las que aquí llegue también se apliquen a otras emociones. ${ }^{3}$ No voy a exponer una teoría detallada y sistemática acerca del odio, ni siquiera intentaré abarcar todas las diferentes clases de odio que podemos encontrar, porque ésta es una emoción con muchas y muy diversas caras - aunque inevitablemente haré una caracterización general de ella a lo largo de este ensayo- ${ }^{4}$ Hay distintos tipos de odio y no todos funcionan de la misma forma ni se manifiestan igual. El odio a hacer quehaceres domésticos, el odio a asistir a reuniones académicas, el que se tiene a un determinado tipo de política o a ciertos programas de televisión, no son iguales al que se manifesta a grupos de personas (a los homosexuales, a los judíos, a los negros) o a alguna persona en particular (al tipo que me robó la novia, al vecino que tiene su horrible música a todo volumen durante todo el día, a la pareja que alguna vez amamos pero que ahora odiamos; o bien, el odio a parientes - que según Tácito es el más violento- e incluso el odio a uno mismo). ${ }^{5}$ En lo sucesivo no voy a considerar los primeros como casos de odio, sino como casos de disgusto o aversión y, siguiendo a Aristóteles, sólo voy a identificar como casos de odio a los segundos: el odio dirigido a una persona específica o a categorías de individuos (neonazis, terroristas, criminales, policías, políticos, abogados, etc.), y también a grupos de individuos. ${ }^{6}$ De hecho, esto nos provee una definición básica del concepto de odio: una actitud emocional negativa hacia otro agente o grupos de agentes que, fundada o infundadamente, se considera que poseen rasgos personales o morales en esencia negativos, o que de algún modo presentan una amenaza potencial o real para los valores e intereses defendidos por el sujeto que odia o para

${ }^{3}$ He tratado de desarrollar esta tesis antes para el caso del amor, véase mi "Love and Rationality. On Some Possible Rational Effects of Love", texto presentado en una sesión de grupo de la Eastern Division Meeting de la American Philosophical Association, Washington, D.C., diciembre de 2003, de donde provienen algunas partes de este ensayo.

${ }^{4}$ Una caracterización pormenorizada del odio se puede encontrar en Jean Hampton y Jeffrie Murphy, Forgiveness and Mercy; véase también Willard Gaylin, Hatred. The Psychological Descent into Violence y Joaci Góes, Anatomia do ódio.

${ }^{5}$ Pascal, en sus Pensamientos, nos dice que "la verdadera y única virtud es odiarse a uno mismo". Sin embargo, el tema de si se puede odiar a uno mismo es discutible. De acuerdo con Aaron Ben-Ze'ev, el odio a uno mismo no es posible, porque "el odio, que requiere una negación comprehensiva del objeto y el deseo de ser disociado de él o incluso de eliminar el objeto, no puede ser autorreferencial" ("Anger and Hate", p. 104).

${ }^{6}$ Cfr. Retórica, II, 1382a2-16. Spinoza coincidiría con Aristóteles cuando dice que: "sólo entiendo por odio el que se dirige a los hombres" (Ética, IV, 45, escolio 1, p. 214). 
su existencia misma - lo que no sucede en otros casos de emociones negativas como el disgusto o la aversión- $-{ }^{7}$ Esta actitud emocional se manifiesta o bien contra agentes individuales, o bien contra agentes colectivos, grupos o categorías de individuos. Es probable que la mejor ejemplificación de este odio a personas o grupos de personas está encarnada en la figura del odio a los enemigos, en la cual voy a enfocar mi atención.

Aunque los diccionarios definen la palabra "enemigo" como aquel contra quien sentimos odio, a quien se quiere hacer daño o a cuyos intereses nos oponemos, tal vez resulte demasiado fuerte decir que el odio se personaliza en la figura del enemigo; los usos que hacemos de las palabras "enemigo" y "enemistad" no siempre implican odio: podemos enemistarnos con quienes nos enojamos, pero sin llegar a odiarlos, o con quien nos resulta antipático; con aquellos a los que les guardamos rencor, a los que envidiamos o con quienes estamos resentidos - aunque los límites entre el odio y el enojo, el rencor, la envidia, el resentimiento o incluso el desprecio, no siempre son muy claros y muchas veces el primero conlleva o desencadena estas otras emociones. Podemos incluso tener enemigos entre la gente contra la que no tenemos ningún sentimiento negativo y a la que queremos y estimamos: Julio César estimaba a muchos de los que finalmente conspiraron contra él y lo mataron; ellos, sin duda, eran sus enemigos y él lo descubrió demasiado tarde. ${ }^{8}$ En lo que sigue voy a circunscribir mi tesis no a cualquier tipo de enemistad, sino sólo a aquellos enemigos con los que el odio es mutuo y con quienes tenemos rivalidad (aunque ésta de por sí no es sinónimo de enemistad, puesto que en competencias tenemos rivales o adversarios a quienes no podríamos propiamente llamar enemigos). ${ }^{9}$ Esta forma de odio tiene, más que cualquier otra, asociaciones con algunas bajas pasiones que nos llevan a perder el control de nosotros mismos, a hacer cosas que en circunstancias normales no haríamos, a no reconocernos en nuestras acciones e incluso conducirnos a nuestra propia perdición, en otras palabras, a comportarnos irracionalmente. De ahora en adelante mi uso de la palabra "odio" se referirá exclusivamente al que tenemos contra personas o grupos que consideramos nuestros enemigos, aunque tal vez algunas de las cosas que diga aquí se puedan aplicar también a otras modalidades de odio, o incluso a otras emociones. De hecho, el odio rara vez se manifiesta al margen de otras emociones; por ello es difícil analizarlo como si fuera una emoción que pudiéramos encontrar en estado puro. En realidad es difícil encontrar emociones en "estado puro"; el odio suele ir acompañado

\footnotetext{
${ }^{7}$ Véanse definiciones similares en Ben-Ze'ev, op. cit., y en Robert C. Solomon, The Passions, pp. 263-267.

${ }^{8}$ Claro que se puede decir que Julio César hizo toda una carrera política basada en la clemencia a sus enemigos y que él bien sabía quién lo odiaba. Cfr. Plutarco, "Vida de Julio César", en Vidas paralelas.

${ }^{9}$ Para un análisis más amplio de la cuestión de los enemigos, véase James A. Aho, This Thing of Darkness. A Sociology of the Enemy.
} 
de emociones como ira, rencor, resentimiento, miedo, celos, envidia o desprecio, entre las más comunes - cuando no de alegría, de regocijo (ante el fracaso ajeno, por ejemplo), de esperanza o incluso de amor (como en las relaciones de amor-odio) - . No es extraño que la literatura sobre el tema haya preferido tratar el odio junto con otras de estas emociones. ${ }^{10}$ Así, mucho de lo que diga sobre el odio puede muy bien aplicarse a algunas de estas otras emociones y ellas pueden también tener determinados efectos que atribuyo al odio.

Conviene hacer una aclaración antes de entrar en materia: hablar de los posibles efectos racionales del odio no significa justificar moralmente las acciones que éste puede generar. La persona que odia es capaz de cometer las más increíbles crueldades y vilezas con tal de satisfacer su odio. Los crímenes de odio o el lenguaje de odio (lo que en inglés se conoce como hate crimes y hate speech) contra minorías raciales o contra gente de diferente orientación sexual son moralmente injustificables; lo mismo sucede con otro tipo de crímenes, venganzas, vendettas, terrorismo o guerras en que la justificación racional de las acciones a las que el odio da lugar no coincide con su justificación moral -aunque muchas veces el que sean moralmente injustificables hace, precisamente, que sean racionalmente injustificables- Contra lo que muchos filósofos han pensado, racionalidad y moralidad no siempre coinciden. Aunque no es mi tema principal en este ensayo, hacia el final diré algo sobre el modo en que el odio puede influir de manera positiva en la moralidad.

Salvo contadas excepciones, las filosofías moderna y contemporánea han dedicado muy poca atención al tema del odio. Incluso el renovado interés en el tema de las emociones se ha dirigido a otras, y es escaso lo que se ha escrito sobre el tema del odio; es notoria la ausencia del término en los índices analíticos de varios de los principales libros sobre emociones que se han publicado recientemente. Me parece que en la Antigüedad se pensó mucho más sobre el odio, las emociones negativas y los enemigos. Tal vez esto se debe a que buena parte de la moral tradicional en la Grecia clásica e incluso en la Roma antigua, entre otras cosas, esperaba que uno

\footnotetext{
${ }^{10}$ Para Spinoza, muchas emociones surgen del odio o se refieren a él: "La envidia, la irrisión, el desprecio, la ira, la venganza y los demás afectos que se refieren al odio o surgen de él, son malos" (Ética, III, 45, corolario 1, p. 214). Varios autores han contrastado el odio con emociones negativas relacionadas. Aristóteles, por ejemplo, habla sobre las diferencias entre el odio y la ira en la Política (V, 1312b33-35). Véase la discusión sobre Aristóteles en Elster, op. cit., pp. 64-68. Séneca habla del odio en muchas ocasiones al referirse a la ira en su tratado sobre esta emoción y, de hecho, muchas de las cosas que dice sobre ella son también aplicables al odio. Charles Darwin estudia las diferencias entre odio y cólera en The Expression of Emotions in Animals and Man, cap. 10. Véase también el artículo ya mencionado de BenZe'ev, "Anger and Hate", y Aurel Kolnai, "The Standard Modes of Aversion: Fear, Disgust and Hatred". Hampton y Murphy analizan las relaciones entre el odio y el resentimiento en Forgiveness and Mercy. Por otro lado, Plutarco aborda las diferencias entre el odio y la envidia en "Sobre la envidia y el odio".
} 
ayudara a sus amigos e hiciera daño a sus enemigos. Muy ligada a estos principios hay una concepción de la justicia regida por la ley del talión, en la cual hay que pagar ojo por ojo y en la que especialmente hay que dañar a quien nos ha perjudicado. Esto se ve con nitidez en las tragedias griegas, donde el asunto del daño a los enemigos es recurrente. ${ }^{11}$ Quizá por eso no es extraño encontrar ya en los filósofos y moralistas antiguos el argumento de que el odio a nuestros enemigos puede tener efectos positivos en la racionalidad de nuestra conducta o en la formación de creencias, y también en la moralidad. En su Moralia, Plutarco escribió lo que sin duda es uno de los mejores ensayos al respecto: "Cómo sacar provecho de los enemigos", y también, aunque a mi parecer un poco menor, "Sobre la envidia y el odio". ${ }^{12}$ Voy a seguir aquí algunas de sus ideas principales, de modo que es posible tomar este ensayo como una variación (en modo racional) sobre temas de Plutarco.

\section{2. ¿Es el odio evaluable racionalmente?}

Es una opinión generalizada que el odio es en sí mismo una emoción irracional. A pesar de que mi propósito principal es hablar acerca de cómo el odio puede ayudar a desarrollar formas racionales de acción y conocimiento, el odio en sí mismo es susceptible, al menos en parte, de ser evaluado y controlado racionalmente. Esto podría extenderse a casi todas las emociones, pues tienen componentes cognoscitivos y evaluativos que las hacen, hasta cierto punto, evaluables en términos racionales. ${ }^{13}$ Digo hasta cierto punto porque hay un factor subjetivo en las emociones del que no puede

${ }^{11}$ Ésta es la tesis de Mary Whitlock Blundell en su Helping Friends and Harming Enemies. A Study in Sophocles and Greek Ethics. Véase también A.P. Burnett, Revenge in Attic and Later Tragedy; W.B. Stanford, Greek Tragedy and the Emotions: An Introductory Study. Encontramos una idea muy similar de lex talionis y de que la conducta que se ha de seguir con los enemigos es odiarlos y hacerles daño en el Antiguo Testamento (e.g. Lv 26:7; Gn 14:19; Is 1:24), donde incluso encontramos la figura de un dios que odia (Dt 1:26). Esta concepción del odio y de los enemigos cambiará con el cristianismo; en $M t$ 5:43-44 Jesucristo dice: "También han oído que antes se dijo: 'Ama a tu amigo y odia a tu enemigo'. Pero yo les digo: Amen a sus enemigos, y oren por quienes los persiguen." (Aunque en el Nuevo Testamento todavía encontramos la figura de un Dios vengativo: "Amados, no os venguéis vosotros mismos, sino dejad lugar a la ira de Dios, porque está escrito: Mía es la venganza; yo pagaré, dice el Señor." [Ro 12:19].)

12 "Cómo sacar provecho de los enemigos"; "On Envy and Hate". A menos que se indique lo contrario, todas las citas de Plutarco provienen de la primera obra; los números de página se refieren a la edición que aparece en la bibliografía y vendrán entre paréntesis después del texto citado. Véase el comentario al segundo texto de Adelmo Barigazzi, "Un esercizio de scuola: distinzione fra invidia e odio".

${ }^{13}$ Sin embargo, las emociones no están constituidas sólo por estados cognoscitivos. Ellas tienen características específicas que nos ayudan a distinguirlas de estados cognoscitivos, tales como las creencias, o de estados conativos como los deseos: sensaciones cualitativas, excitaciones fisiológicas (physiological arousal), expresiones fisiológicas propias, valencia en la escala dolor-placer, y tendencias características a la acción. Véase Jon Elster, Alchemies of the 
darse cuenta cabal en términos de razones, sino en función, por ejemplo, de sensaciones subjetivas o qualia. En el caso del odio, esta emoción involucra creencias y juicios de valor acerca del objeto aborrrecido: el juicio, por ejemplo, de que la persona odiada es inferior, repulsiva, moralmente despreciable o que merece ser odiada. Estas creencias y evaluaciones cuentan como razones para tener la emoción -obviamente, las razones pueden ser buenas o malas-. Sin embargo, hay un hiato entre las razones que tenemos para tener cierta emoción y realmente tenerla; esto se debe, me parece, al componente subjetivo de las emociones, entre otras cosas. El odio no depende enteramente de razones de la misma forma en que lo hacen nuestras creencias y algunos de nuestros deseos. Una mujer, por ejemplo, puede tener suficientes razones, incluso desde su propio punto de vista, para odiar a su violador y, sin embargo, no odiarlo. Aun sabiendo que él, con toda mala intención, la ha violado y le ha destrozado la vida, ella puede no odiarlo. ${ }^{14}$ Del hecho de tener razones para experimentar cierto estado emocional, incluso desde el punto de vista del propio sujeto, no se sigue necesariamente que uno tenga dicho estado emocional.

Una emoción puede ser racionalmente apropiada o no serlo dependiendo de su objeto y de las circunstancias en que ésta aparece; y nuestra evaluación racional de ella está relacionada con cuándo tiene sentido tenerla, $\mathrm{y}$ con el papel que le permitimos desempeñar en nuestras vidas. El objeto de nuestro odio puede ser evaluable con criterios racionales según el contexto en que la emoción aparece, esto es, según las metas y los planes de vida alrededor de los cuales hemos construido nuestra existencia. Podría argumentarse que el odio que alguien puede manifestar no es adecuado, dada la clase de persona que uno es, sus metas o sus circunstancias específicas; sin embargo, el odio no siempre parece tomar esto en cuenta. Así, una emoción en sí misma puede ser evaluada conforme lo adecuado que ella es en relación con su objeto o circunstancias en que se da. Otras veces el odio puede juzgarse como irracional, no porque la emoción que se experimenta sea en sí misma irracional, sino por el papel que el agente le permite tener en su vida. Por ejemplo, una persona cuya existencia se centra en el odio a

Mind, pp. 246 y ss., para una más amplia caracterización de las emociones en estos términos; y también Strong Feelings, pp. 26 y ss.

${ }^{14} \mathrm{Tal}$ vez éste sería el caso de Lucy en la novela de J.M. Coetzee, Disgrace. La reacción de su padre (y del lector) es de extrañeza al ver que no presenta ningún sentimiento negativo ante su violador, a pesar de que sentir odio o alguna otra actitud negativa no sólo sería razonable y justificable, sino hasta de esperarse. Con todo, ella parece justificar las acciones de su violador y no albergar ningún sentimiento de odio hacia él. La situación es complicada puesto que aquí entran en juego muchos factores, como culpas frente a la situación de discriminación racial que prevalecía previamente en Sudáfrica. En otros casos puede haber factores - como el perdón, la piedad y la compasión - por los cuales el odio no surge, a pesar de que pudiera considerarse una emoción retributiva justificada en muchos contextos. Algunas razones por las que podemos perdonar o tener piedad de nuestros enemigos han sido analizadas por Jeffrie Murphy en su "Forgiveness and Resentment" (pp. 24 y ss). 
tal punto que le impide disfrutar las experiencias o beneficios que la vida le ofrece.

Quizás el caso más claro en que el odio tiene una justificación racional sea aquel en que surge como una emoción retributiva, es decir, que presupone un juicio moral acerca de un daño sufrido, indebida o injustificadamente, por el sujeto que odia y que desea compensar el mal padecido mediante el daño a esa otra persona. El que odia desea que la persona odiada baje de nivel o que sufra alguna pena equivalente a la que le inflingió. ${ }^{15}$ Una muestra puede ser la víctima que odia a su torturador, y su odio puede llevarla a buscar retribución en la persona a la que odia.

Así, el odio y las emociones en general pueden ser en sí mismos racionales o irracionales; sin embargo, lo que me interesa resaltar aquí es la racionalidad de las acciones y de las formas de conocimiento a las que pueden dar lugar. El odio puede ayudarnos a desarrollar la racionalidad tanto en su sentido práctico como en el epistémico — si es que uno acepta esta distinción analítica, que aquí adoptaré simplemente con propósitos expositivos- Trataré en primer lugar los efectos racionales que el odio puede tener sobre la racionalidad epistémica, y en la siguiente sección me centraré en la racionalidad práctica.

\section{La racionalidad epistémica: una defensa del odio}

La racionalidad epistémica o teórica se relaciona con el descubrimiento, en una forma precisa y confiable, de cómo es el mundo, y con la forma en que justificamos y expandimos nuestras creencias. En pocas palabras, tiene que ver con la manera en que los agentes forman y justifican creencias.

La tradición dualista que mantiene las emociones y la racionalidad como si fueran opuestas nos dice que las primeras interfieren en la formación y en la justificación objetiva de nuestras creencias: no ayudan a la formación de conocimiento, sino a la de cualquier tipo de prejuicios, exageraciones, paranoias, juicios equivocados o infundados, etc. La percepción que tenemos de la realidad tiende a distorsionarse al calor de un odio intenso o visceral (como también sucede con emociones como la ira, los celos, el pánico, pero también con el amor o la euforia), y la justificación de nuestras creencias tiende a servir a motivos completamente subjetivos. En el odio, uno se inclina a rendir el control intelectual y la justificación de creencias, por ejemplo, a formas de autoengaño o de pensamiento por deseo (lo que en inglés se llama wishful thinking). Por otra parte, se ha dicho, el odio sólo nos permite tener una percepción superficial del objeto aborrecido. Por ejemplo, para Hermann Broch:

\footnotetext{
${ }^{15}$ Murphy ha ahondado en el concepto de emociones retributivas y en la justificación de ciertos tipos de odio en su "Hatred: A Qualified Defense".
} 
el odio sólo percibe la superficie, y la percibe de tal modo que el demonio del odio, a pesar de toda su crueldad inspirando terror, nunca está completamente libre del ridículo y de cierto aspecto diletante. El que odia es alguien que tiene una lupa de aumento, y cuando odia a alguien, conoce precisamente la superficie de esa persona, desde las suelas de sus pies hasta la punta del pelo de la cabeza odiada. ${ }^{16}$

Nuestro conocimiento de la persona aborrecida está prejuiciado por nuestro odio, y fijamos nuestra atención sólo en aquellos aspectos negativos, muchas veces los más superficiales, que justifican nuestros sentimientos. Tal vez está en la naturaleza del odio a nuestros enemigos que la percepción que tenemos de ellos esté distorsionada por los sentimientos que nos producen. El odio a los enemigos puede cegarnos y hacernos pensar inadecuadamente, engañándonos acerca de la naturaleza real del enemigo: exageramos los vicios y las características negativas del enemigo, y nos cegamos a las positivas, convencidos de que es tan despreciable como quisiéramos pensar. Lo anterior puede ser un problema cuando tratamos con enemigos, como dice Michael Corleone en El padrino III: "Never hate your enemies. It affects your judgment." El odio afecta nuestros juicios acerca del enemigo. Cuando se está interesado en su destrucción o en su humillación, tendemos a no verlo como realmente es, sino como nos conviene o como queremos verlo. El odio nos ciega a ciertos aspectos de la realidad, haciendo que nos rehusemos a ver la verdad acerca de la otra persona y, en particular, a ver cualquier rasgo positivo o virtud que éste tenga. Interpretamos los motivos de sus acciones, incluso sus buenas acciones, como actos malintencionados, como formas de maldad, de deseos de venganza, y desechamos todo signo de acercamiento o de buena voluntad como formas de hipocresía o de deseo de hacer daño. Eso nos impide ver sus auténticas intenciones o incluso los modos en que realmente podría llegar a dañarnos: tal vez por eso no deberíamos odiar a nuestros enemigos; puede ser peligroso.

Hay cierta verdad en esta visión tradicional que ve a los que odian como sujetos no muy confiables en su formación de creencias cuando se trata del objeto del odio y en particular de sus enemigos, pues sus creencias van a estar prejuiciadas. ${ }^{17}$ En muchas ocasiones esta imagen es probablemente cierta. Sin embargo, quiero argumentar aquí, contra lo que afirma esta tradición, en favor de aquellos casos en que el odio, más que interferir en

\footnotetext{
${ }^{16}$ Hermann Broch, The Spell, cap. 9. Sin embargo, más adelante, Broch compara el conocimiento superficial del odio con el conocimiento más profundo que, según él, nos proporciona el amor: otra emoción que se suele considerar como generadora de autoengaño y de pensamiento por deseo.

${ }^{17}$ Es interesante la correlación entre prejuicios y odio. Una de las acepciones de la palabra "prejuicio", según el diccionario es: "Sospecha irracional u odio a un grupo particular, raza o religión" (The American Heritage Dictionary of the English Language, 3a. ed., 1992).
} 
la formación de creencias verdaderas y objetivamente justificadas acerca de nuestros enemigos, puede ayudarla.

Las emociones, dice Elster, pueden "facilitar el conocimiento, más que obstruirlo". ${ }^{18}$ La presencia de emociones en el proceso de generación de conocimiento no siempre implica que las creencias resultantes estén distorsionadas, prejuiciadas o justificadas de un modo completamente subjetivo. ${ }^{19}$ El odio puede reorientar la percepción y facilitar una mejor identificación de los aspectos relevantes de nuestros enemigos, y permítaseme ir más lejos y decir que puede ayudarnos a percibir mejor algunos aspectos de la realidad que pasarían inadvertidos sin la intervención de las emociones. El odio no sólo puede ser útil para percibir más finamente rasgos del carácter de nuestros enemigos, sino también peculiaridades del mundo u objetos que pueden servir como instrumentos para cumplir los objetivos prácticos del odio: imponernos al enemigo, debilitar su influencia, dañarlo, perjudicarlo o, en última instancia, destruirlo. Podemos percibir e identificar mejor aquellos objetos y situaciones que la otra persona necesita, desea, ama o son de su interés. Todas esas cosas están también en el interés de quien odia y pueden afectar el modo en que las percibe. La percepción puede estar en función del interés, tanto como de las expectativas: si uno espera ver algo, o si tiene interés en algo, lo va a vislumbrar mucho más fácilmente. Odiar es una forma de tener un interés especial en algo, de estar interesado. Somos mucho más perceptivos a cosas en las que estamos interesados, que nos importan o que valoramos. Las cosas a las que somos indiferentes suelen pasarnos inadvertidas.

De hecho se puede decir que no sólo percibimos, sino que estamos atentos a los aspectos del mundo y a todo lo que esté relacionado con el objeto de nuestro odio. Al poner atención, tenemos una percepción más cuidadosa y fina de las cosas. La atención está guiada por intereses dominantes que nos hacen ser más selectivos respecto de ciertos hechos y de ciertos aspectos del mundo, pero no de otros, y que nos hacen observar más finamente aquellas cosas que nos preocupan. Si no hubiera un interés que guiara nuestra percepción, fallaríamos en advertir rasgos de la realidad a

\footnotetext{
18 Jon Elster, "Rationality, Emotions and Social Norms", p. 34.

${ }^{19}$ Probablemente la forma más básica en que las emociones se involucran en la formación de conocimiento sea lo que se conoce como la "pasión de conocimiento". No sólo nuestros deseos están involucrados en querer descubrir la verdad en ciencia y en otros contextos epistémicos, sino también una literal pasión de conocimiento. Aquí interpreto esta pasión no como una sola, sino como una infinidad de emociones que por lo general están implícitas en procesos de formación de conocimiento: la esperanza de descubrir la verdad, el disgusto ante argumentos falaces, la repulsión frente al engaño, etc. Hay una diversidad de emociones implicadas en procesos cognoscitivos: esperanza, miedo, admiración, alegría y desprecio, entre otras. Estas emociones, junto con distintos intereses prácticos, fungen como estímulos prácticos para la generación de conocimiento. Israel Scheffler ha mostrado "cómo el funcionamiento cognoscitivo emplea e incorpora diversos elementos emocionales" ("In Praise of the Cognitive Emotions", p. 3).
} 
los que estaríamos más atentos de otra manera. Ésta es la concepción de la atención que encontramos en William James:

Mi experiencia es aquello a lo que acepto prestar atención. Sólo aquellas cosas a las que presto atención dan forma a mi mente: sin interés selectivo, la experiencia es un inmenso caos. El interés es lo único que da realce y énfasis, luz y sombra, trasfondo y primer término, en una palabra, perspectiva inteligible. Aunque varía en cada individuo, lo cierto es que sin él la conciencia de cada cual sería una revoltura caótica y gris, imposible de concebir. ${ }^{20}$

Si no pudiéramos seleccionar entre las cosas que percibimos, seríamos una suerte de autómatas reducidos a responder a cualquier estímulo que resultara ser el más fuerte en un momento dado. El odio y las emociones en general manifiestan el interés selectivo que tenemos en aquellas cosas que nos importan y que valoramos -a pesar de que esta valoración sea negativa-. El odio y las emociones, entre otras cosas, dan una estructura o una perspectiva inteligible a nuestra experiencia del mundo. ${ }^{21}$ Ellas nos hacen percibir selectivamente y poner atención en aspectos de la realidad útiles como instrumentos para alcanzar nuestras metas, y al actuar con base en esa información, lo hacemos racionalmente. Al dirigir nuestra atención, las emociones también enmarcan los parámetros que tomamos en consideración en cualquier proceso de conocimiento, y ponen de relieve sólo una pequeña porción de la información disponible. Las emociones hacen más pequeño el número de consideraciones relevantes en el proceso del conocimiento (pero también en la deliberación práctica) y proveen el marco dentro del cual mucho de nuestro conocimiento (así como muchas de nuestras decisiones racionales) tiene lugar. Como nos dice Ronald de Sousa, las emociones limitan "el rango de información que el organismo va a tomar en cuenta, las inferencias tomadas de una infinidad potencial, y el conjunto de opciones de las cuales vamos a escoger". ${ }^{22}$

${ }^{20}$ William James, Principios de psicología, pp. 320 y ss. Las cursivas son del original.

${ }^{21}$ La psicología cognitiva ha estudiado cómo la percepción y la atención pueden estar influidas por diversos fenómenos, tales como estados de ánimo y emociones, que pueden afectar cómo y qué percibimos - para no hablar de cómo las habilidades o una determinada concepción del mundo (una Weltanschauung) puede afectar el modo en que percibimos y ponemos atención a distintas cosas-. Las emociones y los intereses también desempeñan un papel en funciones cognoscitivas como el aprendizaje y la memoria, que pueden ser favorecidas por este proceso de atención. Véase Basic Behavioral Science Research for Mental Health. Sobre cómo las emociones pueden influir y realzar algunos aspectos de nuestra vida sensorial y cognoscitiva en general, véase Paula M. Niedenthal y Shinobu Kitayama (comps.), The Heart's Eye. Emotional Influences in Perception and Attention. Véase también Damasio, op. cit., p. 173.

${ }^{22}$ Ronald de Sousa, The Rationality of Emotion, p. 195. Esta posición ha sido denominada "the search hypothesis of emotions", y ha sido criticada por Dylan Evans ("The Search Hypothesis of Emotions"), quien argumenta que esa hipótesis necesita el apoyo de una teoría acerca de cómo son los mecanismos emocionales que pueden ser capaces de tener este efecto. 
El odio, entonces, hace que nos fijemos en un rango más limitado de opciones de las que nos fijaríamos de otro modo. Hace que nos concentremos más en ciertas características de nuestros enemigos y que en ocasiones lleguemos a conocerlos verdaderamente, ya que el odio puede reorientar nuestra percepción y nuestra atención de modo que obtengamos una imagen más fina de la realidad. Por otro lado, a la hora de actuar, el odio también va a limitar el número de alternativas posibles dentro de las cuales se va a tomar una decisión. En lugar de tener un número infinito de posibilidades de acción, el odio va a reducir considerablemente ese rango.

El proceso de reorientar nuestra percepción y de hacernos más atentos a cierta información y no a otra lo ha ilustrado bien Plutarco: el que odia siempre está al acecho y atento a lo que tiene que ver con el enemigo:

El enemigo está siempre acechando y velando tus cosas y buscando la ocasión por todas partes, recorriendo sistemáticamente tu vida, no mirando sólo a través de la encina... ni a través de ladrillos y piedras, sino también a través de tu amigo, de tu siervo y de todos tus familiares, indagando, en lo que es posible, lo que haces, y escudriñando y explorando tus decisiones. Pues muchas veces, por nuestro abandono y negligencia, no nos enteramos de que nuestros amigos están enfermos y se mueren, pero de los enemigos nos ocupamos incluso de sus sueños. Las enfermedades, los préstamos y las diferencias con las mujeres pasan más desapercibidos a aquellos a quienes les tocan que al enemigo. Sobre todo está pendiente de los yerros y sigue sus huellas. Y así como los buitres son arrastrados por los olores de los cuerpos muertos, pero no captan el olor de los limpios y sanos, así las cosas enfermas, malas y dolorosas de la vida mueven al enemigo, y contra éstas se lanzan los que nos odian, las atacan y las despedazan. (pp. 268-269)

El odio al enemigo pone un interés tal en su vida, sus acciones, su carácter y en todo lo que tenga que ver con su persona, que uno puede llegar a conocerlo mejor de lo que conoce a amigos o familiares $-\mathrm{y}$ sin duda se conoce mucho mejor a los enemigos de lo que se sabe de gente que nos es indiferente, a la que en realidad no tenemos motivos para llegar a conocer. Hay un interés particular en todo lo que concierne al enemigo que hace que se le ponga especial atención. Sólo un buen conocimiento del enemigo permitirá usar más efectivamente la información obtenida con el fin de imponerse a él, dañarlo o destruirlo. (Claro que también podríamos decir que estamos al pendiente de nuestros enemigos no sólo porque queremos vencerlos o destruirlos, sino porque hay cierta curiosidad maliciosa o morbo, alimentados más por la envidia que por el odio, que nos hace regocijarnos al saber de sus desdichas, vicios o defectos.) Sin embargo, en el texto de Plutarco está presente un posible efecto negativo del odio: podemos dejar de ocuparnos de las cosas que tienen que ver con nuestros amigos y familiares; si el odio llega a ocupar tal lugar en nuestras vidas 
que dejamos de ocuparnos de otras cosas que nos competen e interesan, entonces los efectos irracionales del odio pueden sobrepasar sus posibles efectos racionales.

No obstante, ante la perspectiva de que las emociones influyan de manera positiva en nuestros procesos cognoscitivos pueden surgir varias preguntas: ¿cómo estar seguros de que realmente estamos poniendo atención a la evidencia correcta para la justificación de nuestras creencias acerca de nuestros enemigos o acerca del mundo, y no sólo enfocándonos selectivamente en aspectos negativos y pasando por alto otros que podrían ser relevantes, tales como las virtudes y las cualidades del enemigo? ¿Cómo podemos saber que hemos alcanzado un equilibrio entre nuestras creencias acerca del enemigo y la persona real? ¿Cómo establecer si nuestras creencias son verdaderas y nuestra percepción confiable, y que no hemos entrado en un proceso de autoengaño o de pensamiento por deseo? Esto es muy difícil de identificar, si no imposible, desde la perspectiva de la primera persona, es decir, de aquel que odia. Pero no creo que un punto de vista externo pueda ser siempre de mucha utilidad aquí, dado que mucho de lo que vemos en el enemigo es precisamente accesible sólo para quien accede al estado emocional. Quien odia tiene que conocerse muy bien a sí mismo y al enemigo para saber cuándo se está engañando y cuándo sus creencias basadas en su emoción son fieles y están propiamente justificadas. Quizá algunas de sus creencias van a ser producto del primer proceso y algunas del segundo. El odio tiende de hecho a interferir en la manera en que formamos creencias y percibimos el mundo, a través de autoengaño y pensamiento por deseo; pero incluso entonces hay ciertos puntos en la percepción y en la acción en los cuales el odio puede ayudar a la formación racional de creencias. A fin de cuentas, la racionalidad no es un fenómeno completamente unitario que incluya todos nuestros pensamientos y nuestras acciones, sino que trabaja más bien, digamos, en una forma molecular. Mientras somos irracionales en determinados aspectos de nuestra vida, somos racionales en otros; mientras que hay mecanismos en los cuales las emociones dan lugar a efectos irracionales, hay otros en que esos efectos pueden considerarse racionales, dada la manera en que las emociones ayudan a una adecuada formación de creencias. En tanto que algunas de nuestras creencias acerca del enemigo pueden deberse a un proceso de autoengaño o a prejuicios producidos por el odio, otras pueden muy bien ser verdaderas y estar del todo justificadas. Claro que, en ocasiones, la línea entre estas dos no es tan clara como quisiéramos.

\section{Tendencias a la acción y racionalidad práctica}

Cuando se trata del odio, muchas veces el tipo de conducta más racional que podemos asumir es no dejarnos llevar por nuestra emoción, y simple- 
mente tratar de omitir cualquier acción, procurar olvidar, perdonar, distanciarnos de la persona a la que odiamos. Tal vez lo más racional sea tratar de controlar nuestro odio, intentar entenderlo y hacerlo desaparecer. Sin embargo, éste no es el caso que me interesa analizar aquí, es decir, no el de cómo la razón se impone a la pasión, sino el de cómo esta última genera formas racionales de comportamiento.

Antes que nada, quiero presentar la teoría tradicional que piensa el odio como generador de conducta irracional. Como dije antes, no pretendo negar la idea de que el odio puede generar patrones de conducta irracionales o puede llevarnos a una justificación irracional de nuestras creencias; sólo deseo argumentar en favor de la existencia del mecanismo opuesto. Según la teoría tradicional, el odio nos puede llevar a hacer cosas irracionales, a perder el control sobre nuestras acciones; más allá de todo buen sentido, puede llevarnos a tener actitudes moralmente injustificables, a hacer cosas horribles y crueles, e incluso nos puede llevar a la autodestrucción o a la perdición. Muchas veces hace que nos comportemos en formas que no representan nuestros mejores intereses o que se alejan de las metas en razón de las cuales hemos construido nuestra vida. Los casos de venganza generados por odio a un enemigo podrían servir aquí como muestras paradigmáticas de odio que genera conductas irracionales. Las palabras de Séneca sobre la ira pueden aplicarse perfectamente al odio: esta pasión "es todo arrebato y a impulsos del despecho; en absoluto humana, furiosa en su ansia de guerras, sangre, tormentos; con tal de dañar al otro, descuidada de sí, precipitándose sobre sus propios dardos y ávida de una venganza que ha de arrastrar con ella al vengador". ${ }^{23}$ Tal vez uno de los ejemplos paradigmáticos del odio que lleva a cometer actos que bien podríamos calificar de irracionales y destructivos sea el odio de Medea a Jasón: Medea mata a los hijos que había tenido con Jasón como venganza cuando él la abandona por otra mujer, Glauce, con quien Jasón tendría un matrimonio más ventajoso políticamente. Medea también asesina a Glauce con su magia de hechicera. Sin duda, aquí encontramos también sentimientos de rencor, ira, celos, resentimiento, e incluso de temor ante el destino que podrían tener sus propios hijos si ella se viera desterrada tras el nuevo matrimonio de Jasón, pero igualmente hallamos una modalidad extrema de odio, como Jasón mismo la llama (mîsos) hacia el final de la tragedia de Eurípides (1323), cuando ella ya ha consumado su venganza. El odio de Medea tal vez sea la transfiguración de un amor tan violento como el que ella tuvo antes por Jasón. Este amor ya había tenido efectos irracionales y destructivos: Medea había traicionado a su pueblo y a su padre, y había matado a su propio hermano cortándolo en pedazos, todo con tal de ayudar a Jasón a encontrar el vellocino de oro. Jasón finalmente le paga con

${ }^{23}$ Séneca, De la cólera, I, 1, p. 33. 
una traición. La conducta de Medea es tal vez uno de los mejores ejemplos de los efectos irracionales que pueden tener las emociones. No obstante, desde otro punto de vista se podría muy bien argumentar que, a partir de su odio, ella razona el camino que debe seguir y escoge el castigo de Jasón de manera racional. ${ }^{24}$

La teoría tradicional de las emociones ha destacado el mecanismo con el cual el odio puede originar conductas irracionales; aquí subrayaré el mecanismo opuesto: aquel en que el odio puede conducir a patrones racionales de conducta. En este último caso, tal vez la manera más simple de ayuda a la racionalidad práctica sea a través de una forma instrumental o estratégica de racionalidad.

Empecemos por las tendencias a la acción propias del odio. Como dije antes, es viable definir el odio como una actitud emocional negativa hacia otro agente, individual o colectivo, a quien se considera que posee rasgos personales o morales fundamentalmente negativos, que representan una amenaza para la existencia o la supervivencia del sujeto que odia (como sucede en las guerras, en odios hereditarios —en inglés feuds - o en una vendetta), o tan sólo porque representan una amenaza a los valores e intereses (morales, religiosos, económicos, etc.) que defiende el sujeto. Todo esto hace que en el odio se manifiesten deseos y tendencias a la acción característicos; según Plutarco, "la intención del que odia es hacer daño, y el significado del odio es así definido: es cierta disposición e intención que aguarda la oportunidad de dañar"; ${ }^{25}$ según Spinoza, "quien odia se esfuerza por alejar y destruir la cosa que odia". ${ }^{26}$ Así, podríamos caracterizar las tendencias a la acción del odio de la siguiente manera: alejar, reducir o eliminar la influencia de la persona a la que se odia, lo cual puede implicar desde tratar de vencerla, imponerse a ella o hacerla quedar mal o en ridículo, hasta dañarla, herirla y finalmente destruirla. Éstos son los fines que impone el odio a la razón, aunque la razón, como dije antes, puede sobreponer al odio la tolerancia, el perdón, el distanciamiento, la reconciliación o la clemencia.

La ira puede generar deseos y tendencias a la acción similares a los del odio, aunque implica una evaluación de acciones o sucesos, mientras que el odio conlleva una evaluación del sujeto odiado. ${ }^{27}$ Con todo, como lo indica Aristóteles en la Política, la ira "muchas veces es incluso más activa que el odio, pues ataca con más vigor debido a que la pasión no se sirve de

${ }^{24}$ Véase el análisis del odio de Medea en Stanford, op. cit., pp. 33 y ss.

${ }^{25}$ Plutarco, "On Envy and Hate", p. 107.

${ }^{26}$ Spinoza, Ética, III, 13, escolio; véase también IV, 45.

${ }^{27}$ Cfr. Ben-Ze'ev, op. cit. Véase también la opinión de Nico Fridja, para quien "el odio es a la ira lo que la vergüenza a la culpa: el primer miembro de cada par está basado en una 'evaluación de objeto', el segundo en una 'evaluación de suceso'. El odio dice 'él es malo', la ira, 'él me hizo algo malo'. De forma análoga, la vergüenza refleja la idea 'yo soy malo', la culpa, 'hice algo malo'" (The Emotions, p. 212). 
razonamiento [...]. En cambio, el odio es más calculador, pues la ira lleva consigo el dolor, de modo que no es fácil razonar, mientras que el odio está exento de dolor." 28 Aunque se puede poner en duda que el odio esté efectivamente exento de dolor, como afirma Aristóteles, él da la pauta para el aspecto que quiero destacar: el odio es más calculador. Podríamos decir que el odio nos impone ciertos requisitos prácticos una vez establecidos los fines: tenemos que comportarnos en formas en que efectivamente nos impongamos, dañemos, hiramos o destruyamos a la persona odiada, al enemigo.

Quedarnos impasibles cuando un odio justificado nos domina podría hacernos poner en duda que haya siempre tales tendencias a la acción, pero eso puede tener por lo menos cuatro explicaciones: ${ }^{29}$ (1) Tal vez podría querer decir que nos encontramos en una situación de inferioridad tal en la cual es más prudente no actuar, o nos percibimos a nosotros mismos como impotentes para actuar. Puede incluso suceder que sea imposible la revancha, porque el sujeto odiado está en una posición inalcanzable o porque él es indiferente al mal que le queramos infligir. (2) Es demasiado costosa la revancha: en un análisis de costo-beneficio tal vez uno sale perdiendo dados toda la energía, el tiempo, el dinero, etc., que emplearía en el desquite (aunque en ocasiones el odio puede llevarnos a la actitud, por demás irracional, de hacer daño al enemigo o vengarse "cueste lo que cueste"). A esto se refiere Spinoza cuando dice: "Quien tiene odio a alguien, se esforzará en hacerle mal, a menos que tema que de ahí le surja un mal mayor."30 (3) La decencia moral puede imponernos restricciones: éste es el caso en que, a pesar de que uno podría hacer daño al enemigo con impunidad, se abstiene por razones morales, tal vez para mantener la propia integridad moral, por ejemplo. (4) Finalmente, eso podría querer decir que el supuesto enemigo nos es indiferente, pero esto nos haría dudar de que esa persona sea verdaderamente un enemigo, pues nadie que nos sea indiferente puede ser visto como un enemigo.

Pero si nada de esto sucede, el odio se encauza a ciertas formas particulares de acción y aquí es donde entra la racionalidad en su sentido instrumental. Una vez establecido el fin a partir del estado emocional, éste puede generar formas instrumentales de racionalidad con tal de verse satisfecho. Podríamos traducir esto como un cálculo de utilidad esperada, mediante estrategias con las que hacemos un balance de los medios con lo que vamos a alcanzar los fines fijados por nuestra emoción, siendo la acción más racional aquella que tenga la utilidad esperada más alta. No todos los medios son igualmente conducentes a nuestros fines; el trabajo

${ }^{28}$ Aristóteles, Política, V, 1312b33-35.

${ }^{29}$ Sigo aquí parcialmente la postura de Murphy en su "Hatred: A Qualified Defense" (pp. 104-107).

${ }^{30}$ Spinoza, op. cit., III, 39. 
de la racionalidad es estimar cuáles son los mejores medios para alcanzar nuestros fines.

Tal vez todo esto parezca demasiado maquiavélico: establecer cuáles son los medios mejores, más convenientes, eficientes, económicos... para hacer daño, herir o eliminar al enemigo. Esto implica evaluar las consecuencias, los posibles costos y los beneficios que tal o cual curso de acción pueda tener. Sin duda se trata de una forma de desarrollo de racionalidad, la más simple indudablemente; pero puede haber otras tal vez menos evidentes en que el odio puede ayudar a este desarrollo. El odio nos hace más calculadores, pero esto puede significar que también nos hace más prudentes, como escribe Plutarco al preguntarse si los efectos epistémicos del odio a los enemigos pueden ser provechosos:

Sin duda [éstos son provechosos], procurando vivir con precaución y preocupándose de uno mismo, y tratando de no hacer ni decir nada con indeferencia e irreflexivamente, sino siempre mantener cuidadosamente, como en un régimen severo, la vida irreprensible. Pues el cuidado, que así reduce las pasiones y conserva el razonamiento, produce una costumbre y una resolución de vivir bien e irreprochablemente. Y, así como las ciudades castigadas por las luchas con los vecinos y las expediciones militares continuas se contentaron con unas buenas leyes y un gobierno sano, del mismo modo los que son obligados por algunas enemistades a ser sobrios en su vida y a guardarse de ser negligentes y confiados, y hacer cada cosa con utilidad, sin darse cuenta son llevados por la costumbre a no cometer ninguna falta y a ordenar su conducta, por poco que la razón les ayude. Pues el dicho: "Ciertamente se alegrarían Príamo y los hijos de Príamo",* éstos siempre lo tienen a mano, los vuelve, los desvía y los aleja de aquellas cosas de las que sus enemigos se alegran y se ríen. Y vemos que los artistas dionisíacos ${ }^{\dagger}$ muchas veces contienden en los teatros entre ellos mismos con negligencia, sin ánimo y sin esmero, pero cuando existe contienda y porfía con otros, no sólo se cuidan de estar más atentos ellos mismos, sino que también se cuidan más de su instrumento, tensando las cuerdas y ajustando y tocando sus flautas con gran armonía. Por eso, el que ve que su enemigo es un rival de su vida y su fama, pone más atención en sí mismo, examina con cuidado sus acciones y ordena su vida. Puesto que también esto es propio del vicio, avergonzarse ante los enemigos más que ante los amigos por los errores que cometemos. (pp. 269-270)

El odio a los enemigos nos obliga a ser más conscientes de los defectos que han provocado su censura, consigue que lleguemos a conocernos más profundamente y a saber ejercitar control sobre nosotros mismos y nos

\footnotetext{
* Príamo fue padre de Paris, Héctor y Casandra y rey de Troya durante la guerra con los aqueos que relata Homero en La Ilíada. El pasaje se refiere a la prudencia que debían tener los aqueos para no dar motivo de burla a los troyanos.

${ }^{\dagger}$ Miembros de un poderoso gremio en el que se formaban actores y músicos itinerantes.
} 
enseña a ser discretos frente a los reproches, y dice Plutarco más adelante, a comportarnos mejor con nuestros amigos y familiares. La competencia que genera el odio a los enemigos - aunque también podríamos añadir el miedo al ridículo frente a ellos y a pasar alguna situación vergonzosa que pueda dar lugar a reproches - nos hace ser más prudentes: nos hace tratar de ser mejores en todo aquello en lo que podemos ser comparados con ellos, hace que tratemos de vivir una vida irreprochable, en la cual no cometamos faltas, y a ordenar nuestra conducta. Las enemistades nos obligan a ser sobrios, a ser más conscientes de nosotros mismos, a ser más cuidadosos con lo que hacemos y decimos. En otras palabras, no sólo nos hace ser más prudentes, sino también más virtuosos, y si consideramos el odio y tener enemigos como un rasgo no virtuoso de carácter, esto nos haría poner en duda la doctrina clásica de la unidad de las virtudes, según la cual éstas se implican unas a otras unitariamente, de modo que un agente virtuoso no puede tener vicio alguno.

La competencia, como los apologistas del libre mercado han recalcado, es la madre de la invención y la creatividad (aunque en ocasiones la competencia puede resultar en lo contrario, como sucede en muchos sistemas académicos de evaluación, que tienden a matar la invención y la creatividad). Pero cuando tiene el efecto positivo es cuando podemos suscribir las palabras de Jean Genet, quien, supongo, pensaba en algo así cuando escribió en su obra de teatro Los negros que "Lo que necesitamos es odio. De él nacen nuestras ideas." La competencia y la rivalidad que puede conllevar el odio a los enemigos son capaces de generar nuevas estrategias, ideas, teorías, arte, etc. Éstas pueden nacer del deseo de vencer al enemigo, imponerse a él o incluso dañarlo mostrando que somos superiores, más originales, creativos o hábiles. Con frecuencia, el odio al enemigo entraña una comparación y una competencia entre el sujeto que odia y el aborrecido; quien odia quiere ser superior e imponerse al enemigo y para ello es necesaria una constante comparación -la comparación y la competencia son probablemente mucho más evidentes en la envidia, pero también están muy presentes en el odio-. ${ }^{31}$ Esta comparación tiene el fin de marcar una diferencia entre quien odia y el enemigo: "odiamos a aquellos que nos hacen sentir nuestra propia inferioridad", dice la sabiduría popular. ${ }^{32}$ Quien odia siempre querrá ocupar una posición de superioridad con respecto al enemigo — tal vez porque odiar

\footnotetext{
${ }^{31}$ El elemento de comparación inherente al odio ha sido analizado por Jean Hampton en su "Forgiveness, Resentment, and Hatred", pp. 60-79.

${ }^{32}$ Es cierto aquello de que el odio nos puede hacer infelices: el odio, y la comparación que conlleva, puede provocar que seamos infelices cuando en la comparación resultamos en desventaja. Tal vez por eso dice Séneca: "Que nuestras cosas nos complazcan sin la comparación, nunca será feliz a quien le atormente otro más feliz" (De la cólera, III, 30, p. 147).
} 
ocupando una posición de inferioridad no puede llevarnos muy lejoso en última instancia querrá hacer desaparecer la relación eliminando al enemigo. ${ }^{33}$

Sin embargo, se ha dicho que la eliminación del enemigo se nos presenta con una paradoja. Aunque es posible dañarlo y rebajarlo de modos perfectamente racionales, el odio que lleva a la destrucción del sujeto aborrecido puede ser contradictorio en sí mismo. La paradoja del odio es la siguiente: la más extrema consumación del odio, es decir, la destrucción del sujeto odiado, deja sin objeto al que odia y sin un parámetro ante el cual medirse - algo similar a lo que sucede en la dialéctica del amo y del esclavo de Hegel-.${ }^{34}$ Esto es claro en el poema "The Prohibition", de John Donne:

Take heed of hating me,

Or too much triumph in the victory.

Not that I shall be mine own officer,

And hate with hate again retaliate;

But thou wilt lose the style of conqueror,

If I, thy conquest, perish by thy hate.

Then, lest my being nothing lessen thee, If thou hate me, take heed of hating me. ${ }^{35}$

Sin persona odiada no hay odio. Para mantenerlo, quien odia no debe llegar al punto de destruir el objeto de su odio, sin el cual su emoción no tendría sentido - aunque cabría preguntar si el odio puede sobrevivir a la muerte del sujeto odiado- - . El odio, para su misma existencia, parece necesitar a la persona odiada, al enemigo. Tal vez el odio más racional no destruye nunca el objeto de odio, el enemigo. Pero quizá una respuesta sencilla a esta paradoja es que en la realidad, cuando el objeto de nuestro odio desaparece, no parece haber nada más fácil que adoptar un nuevo objeto de odio. ${ }^{36}$

${ }^{33}$ Pero muchas veces, para verdaderamente saber qué posición ocupa uno en la comparación con el enemigo y para imponerse a él, como dije antes, se requiere un buen conocimiento de éste, e idealmente de uno mismo. Como dice el general chino del siglo VI a.C., Sun Tzu: "Si conoces al enemigo y te conoces a ti mismo, no necesitas temer el resultado de un centenar de batallas. Si te conoces a ti mismo, pero no al enemigo, por cada victoria ganada también sufrirás una derrota. Si no conoces ni al enemigo ni a ti mismo, sucumbirás en cada batalla" (El arte de la guerra, cap. 3, axioma 18).

34 Jon Elster analiza el tema del odio en términos de la dialéctica hegeliana del amo y del esclavo en Ulysses and the Sirens, cap. 4.

35 "Ten cuidado al odiarme, / Y no pongas mucho triunfo en la victoria. / No porque yo vaya a ser mi propio ejecutor, / Y devolver una vez más odio con odio; / Pero tú perderás tu estilo de conquistador, / Si yo, tu conquista, pereciera por tu odio. / Entonces, para que mi aniquilación no te rebaje, / Si me odias, ten cuidado al odiarme." La versión al español, muy libre, es mía.

${ }^{36}$ La figura del enemigo cumple otras funciones además de las de posible ayuda al desarrollo racional de la conducta y de la formación de creencias y de la moralidad. La figura 


\section{Los que quieran salvarse necesitan amigos auténticos o enemigos ardientes}

Por lo general se ha criticado al odio desde las perspectivas de la moralidad y de la civilidad por sus efectos nocivos: el odio no es moralmente bueno porque tiene la finalidad de hacer daño y destruir a la persona odiada, y eso no puede ser bueno. ${ }^{37} \mathrm{El}$ odio genera hostilidad, conflictos, enemistades, crímenes, peleas, venganzas, terrorismo, guerras y destrucción, entre otras muchas desgracias que, sin duda, las más de las veces conllevan una conducta irracional e inmoral. El odio también produce rasgos de carácter no virtuosos, o moralmente viciosos, en los agentes que odian: agresividad y violencia, entre otros. Sin embargo, el odio puede llegar a tener consecuencias positivas para nuestra conducta moral.

Es posible que el odio a los enemigos se transfigure en virtud, por lo menos así podemos interpretar las palabras de Plutarco cuando nos dice: "Si quieres afligir al que te odia, no lo taches de hombre degenerado ni cobarde, ni libertino, ni bufón, ni innoble, sino tú mismo sé un hombre, muéstrate moderado, sincero, y trata con amabilidad y justicia a los que tienen trato contigo." (271) También podríamos decir que una forma de mostrar superioridad sobre un enemigo es que, si en efecto él es cobarde, libertino o innoble, nosotros no nos rebajamos a insultarlo o criticarlo, sino que nos ponemos por encima de su nivel y lo tratamos con civilidad y amabilidad; eso, según Plutarco, verdaderamente lo afligirá, es decir, si es que en realidad hay rivalidad y enemistad mutua (aunque también es muy probable que nuestra conducta lo tenga sin cuidado). Tal vez este tipo de comportamiento pueda tacharse de hipócrita más que de virtuoso; pero la hipocresía o el disimulo pueden en ocasiones ser una virtud de civilidad. Muchas veces es mala estrategia exhibir nuestros sentimientos en vez de disimularlos: si espontáneamente mostráramos siempre nuestras emociones o dijéramos todo lo que pensamos, nos meteríamos en demasiados problemas y haríamos demasiado difícil la coexistencia con otros, en particular cuando hay odio de por medio. ${ }^{38}$

del enemigo desempeña un papel significativo en la construcción de la identidad personal y colectiva. El enemigo representa la figura del otro, del diferente, aquel ante quien construimos nuestra propia identidad. Somos quienes somos porque somos diferentes del otro, el enemigo. Tal vez por eso se ha dicho en repetidas ocasiones que necesitamos a los enemigos y que por eso no es conveniente exterminarlos. Esta función de la figura del enemigo en la construcción de la identidad también es definitoria de las relaciones políticas, según autores como Carl Schmitt. Lo que define la política, dice Schmitt en El concepto de lo político, se puede reducir a la relación amigo-enemigo. Sería posible argumentar en favor de las posibilidades de acción racional que podría generar el odio a los enemigos en el terreno de la política, pero baste aquí mencionar estos ámbitos en que la figura del enemigo desempeña un papel importante, pues éstos son temas que exceden las pretensiones del presente trabajo.

${ }^{37}$ Cfr. Spinoza, Ética, III, 45.

${ }^{38}$ Elster trata la idea de que la hipocresía tiene una fuerza civilizadora en Alchemies of the Mind, p. 402. 
Pero si la anterior es una virtud cuestionable, es posible argumentar que el odio puede dar lugar a otro tipo de virtudes. Si efectivamente es cierto que el odio a los enemigos nos puede obligar a ser más conscientes de nuestros propios defectos, puede conseguir que lleguemos a conocernos mejor, a saber ejercer el control de nosotros mismos, y nos enseña a ser discretos frente a los reproches; entonces, como nos dice Plutarco, los enemigos son necesarios en el camino de la virtud: "Antístenes dijo muy bien que los que quieren salvarse necesitan amigos auténticos o enemigos ardientes. Pues los unos amonestan a los que se equivocan, y los otros, al censurarlos, los alejan del error" (273). ${ }^{39}$ El miedo a exponernos a una situación vergonzosa frente a nuestros enemigos, a ser tachados de inferiores, puede hacer que nos alejemos del vicio y del error. El miedo a la vergüenza y a la crítica de otros es sin duda uno de los grandes promotores del comportamiento estratégico, pero también del moral.

Antes hablé del conocimiento del enemigo, el cual puede tener consecuencias prácticas: un buen conocimiento del enemigo no sólo podría ayudarnos en nuestras intenciones para con él —por más destructivas que éstas sean-, o incluso llegar a salvarnos; pero también, como hace notar Plutarco, este conocimiento podría tener consecuencias positivas para la vida moral de quien odia:

Si uno no está ciego, en relación con lo que odia, sino que se convierte en espectador justo de la vida, del carácter, de las palabras y de los hechos de los demás, observará que la mayoría de las cosas que provocan su envidia les sobrevinieron a sus poseedores por su diligencia, previsión y acciones nobles, $\mathrm{y}$, esforzándose por estas cosas, ejercitará su amor a la honra y al honor, y echará fuera su indiferencia y su pereza. (p. 282)

Tal vez Plutarco es demasiado optimista o demasiado ingenuo al pensar que las cosas que provocan la envidia de quien odia son producto de las virtudes del enemigo; muchas veces el odio y la envidia se deben precisamente a lo inmerecido de esas cosas que provocan envidia. Pero aceptando que existe en algunos casos la relación que plantea Plutarco, entonces la competencia generada por el odio nos podría hacer desear y honrar aquellas virtudes que han dado al enemigo aquello que tanto envidiamos y por lo que tanto lo odiamos. Con tal de ponernos en una posición de superioridad con respecto a él, adquiriríamos las virtudes que

39 Antístenes fue un filósofo griego que vivió entre 444 y 371, aproximadamente, y que fundó la escuela cínica. Esta idea es similar a la de Joyce Carol Oates, para quien "Nuestro enemigo es tradicionalmente nuestro salvador, al impedirnos caer en la superficialidad" (citada en "Master Race", Partisan Review 50th Anniversary Edition, William Phillips (comp.), 1985). 
lo hacen superior y las ejercitaríamos con tal de hacernos iguales o superiores a él. En este caso, el odio no solamente tendría efectos positivos sobre la racionalidad, sino también sobre la moralidad de aquel que odia.

Los casos a los que he aludido son sólo un mecanismo diferente del que ha destacado la visión tradicional de las emociones y del odio en particular. El odio puede dar lugar a cualquiera de estos dos mecanismos, y es difícil saber por qué se produce uno en lugar del otro. Muchos dirán que lo descrito no es la regla, sino la excepción; pero, incluso así, es bueno no olvidar que hay casos en que las emociones, en vez de obstruir procesos racionales de pensamiento y acción, los facilitan, y en que emociones negativas, en vez de dar lugar a acciones inmorales, las posibilitan; tampoco hay que olvidar que las interrelaciones del pensamiento reflexivo (tanto en su forma teórica como en la práctica, si queremos mantener esa distinción) con las emociones, son más complejas de lo que se podría pensaría en un primer momento. ${ }^{40}$

\section{BIBLIOGRAFÍA}

Aho, James A., This Thing of Darkness. A Sociology of the Enemy, University of Washington Press, Seattle/Londres, 1994.

Aristóteles, Política, trad. M. García Valdés, Gredos, Madrid, 1988.

— Retórica, trad. A. Ramírez Trejo, unAm, México, 2002.

Barigazzi, Adelmo, "Un esercizio de scuola: distinzione fra invidia e odio", Studi su Plutarco, Università degli Studi di Firenze, Florencia, 1994, pp. 57-73.

Basic Behavioral Science Research for Mental Health. A Report of the National Advisory Mental Health Council, NIH publication no. 96-3682, 1995.

Ben-Ze'ev, Aaron, "Anger and Hate", Journal of Social Philosophy, vol. 23, pp. 85110, 1992 (reimpreso en The Subtlety of Emotions, The MIT Press, Cambridge, Mass., 2000).

Blundell, Mary Whitlock, Helping Friends and Harming Enemies. A Study in Sophocles and Greek Ethics, Cambridge University Press, Cambridge, 1989.

Broch, Hermann, The Spell, Farrar, Straus, and Giroux, Nueva York, 1987.

Burnett, A.P., Revenge in Attic and Later Tragedy, University of California Press, Berkeley, 1998.

Coetzee, J.M., Disgrace, Penguin, Nueva York, 1999.

Damasio, Antonio, Descartes' Error. Emotion, Reason, and the Human Brain, Putnam, Nueva York, 1994.

Darwin, Charles, The Expression of Emotions in Animals and Man, 3a. ed., Oxford University Press, 1998.

Elster, Jon, Ulysses and the Sirens, Cambridge University Press, Cambridge, 1979.

${ }^{40}$ Quiero agradecer a José Alberto Barrañón, Francisco Barrenechea, Mark Platts y a un dictaminador anónimo de esta revista sus comentarios y críticas a versiones anteriores de este ensayo. 
Elster, Jon, "Rationality, Emotions and Social Norms", Synthese, vol. 98, pp. 21-49, 1994.

—, Alchemies of the Mind. Rationality and the Emotions, Cambridge University Press, Nueva York, 1999.

— Strong Feelings. Emotion, Addiction, and Human Behavior, The MIT Press, Cambridge, Mass., 1999.

Evans, Dylan, "The Search Hypothesis of Emotions", British Journal of the Philosophy of Science, vol. 53, no. 4, 2002, pp. 497-509.

Fridja, Nico, The Emotions, Cambridge University Press, Cambridge, 1986.

Gaylin, Willard, Hatred. The Psychological Descent into Violence, Public Affairs, Nueva York, 2003.

Góes, Joaci, Anatomia do ódio. Na familia, no trabalho, na sociedade, Topbooks, Rio de Janeiro, 2004.

Hamlyn, D.W., "The Phenomena of Love and Hate", Perception, Learning and the Self, Routledge and Kegan Paul, Londres, 1983, pp. 267-285.

Hampton, Jean, "Forgiveness, Resentment, and Hatred", en Hampton y Murphy, Forgiveness and Mercy, pp. 35-87.

Hampton, Jean y Jeffrie Murphy, Forgiveness and Mercy, Cambridge University Press, Cambridge, 1988.

James, William, Principios de psicología, Fondo de Cultura Económica, México, 1989.

Kolnai, Aurel, "The Standard Modes of Aversion: Fear, Disgust and Hatred", Mind, vol. 107, pp. 581-595, 1998.

LeDoux, Joseph, The Emotional Brain: The Mysterious Underpinnings of Emotional Life, Simon and Schuster, Nueva York, 1996.

Murphy, Jeffrie, "Forgiveness and Resentment", en Hampton y Murphy, Forgiveness and Mercy, pp. 14-30.

—_, "Hatred: A Qualified Defense", en Hampton y Murphy, Forgiveness and Mercy, pp. 88-110.

Niedenthal, Paula M. y Shinobu Kitayama (comps.), The Hearth's Eye. Emotional Influences in Perception and Attention, Academic Press, San Diego, 1994.

Ortiz-Millán, Gustavo, "Love and Rationality. On Some Possible Rational Effects of Love", inédito.

Plutarco, "Cómo sacar provecho de los enemigos", Obras morales y de costumbres (Moralia), vol. I, trad. C. Morales Otal y J. García López, Gredos, Madrid, 2001, pp. 261-283.

— - "On Envy and Hate", Plutarch's Moralia, VII, trad. P.H. de Lacy y B. Einarson, Loeb Classical Library, Heinemann-Harvard University Press, Cambridge, Mass., 1959, pp. 92-107.

—_, "Vida de Julio César", Vidas paralelas, Porrúa, México, 1993.

Scheffler, Israel, "In Praise of the Cognitive Emotions", In Praise of the Cognitive Emotions, Routledge, Nueva York/Londres, 1991, pp. 3-17.

Schmitt, Carl, El concepto de lo político, trad. Rafael Agapito, Alianza, Madrid, 1991.

Séneca, De la cólera, trad. E. Otón Sobrino, Alianza, Madrid, 1986.

Solomon, Robert C., The Passions, Hackett, Indianápolis, 1993.

Sousa, Ronald de, The Rationality of Emotion, The MIT Press, Cambridge, Mass., 1987. 
Spinoza, Baruch, Ética, trad. Atilano Domínguez, Trotta, Madrid, 2000.

Stanford, W.B., Greek Tragedy and the Emotions: An Introductory Study, Routledge and Kegan Paul, Londres, 1984.

Sun Tzu, El arte de la guerra, trad. Alfonso Colodrón, Edaf, Madrid, 1999.

Recibido el 14 de enero de 2004; aceptado el 26 de abril de 2004 